\title{
THE EFFECT OF SPINAL ANAESTHESIA ON BLOOD VOLUME IN MAN ${ }^{\circ}$
}

\author{
D. J. ARmstrong, M.D., AND D. C. Finlayson, M.D., F.R.C.P.(c) $†$
}

Hypotension resulting from vasodilatation secondary to sympathetic blockade is a problem which may be associated with the use of spinal anaesthesia. In most cases, it can be readily controlled by either parenteral fluids or a vasopressor. Hydration sufficient to fill a dilated vascular tree may present a hazard to the cardiac patient when the block wears off, whereas the use of a prophylactic vasopressor does not give rise to this particular problem.

The effect of spinal anaesthesia on the whole blood volume is not clearly documented. Results from previous studies ${ }^{1-5}$ are conflicting due to variations in species studied, premedication, types and dosages of anaesthetic agents, associated surgical procedures, and techniques used for blood volume measurements. This study therefore seeks to evaluate the effect on the plasma and red cell volumes of a widely used method of anaesthesia, employing a prophylactic vasopressor under standardized conditions for measurements.

\section{METHODS}

\section{Patients}

Nineteen previously ambulatory male patients, 59 to 87 years of age, had an observation cystoscopy performed under spinal anaesthesia, with each study begun at 10 A.M. These patients were free of significant respiratory or metabolic disease, and their cardiovascular status was stable, with no clinical signs of heart failure. None were receiving digitalis or diuretics. They were not premedicated, and had been fasting for 10 to 12 hours.

\section{Anaesthesia}

Anaesthesia was administered at the L 3-4 or L 4-5 intervertebral space, using a 26-gauge needle and a 21-gauge introducer. Depending upon the patient's height, and with the intent of producing sensory blockade to the level of the xiphoid, 10 to $15 \mathrm{mg}$. of 1 per cent tetracaine hydrochloride, and an equal volume of 10 per cent dextrose, were injected into the subarachnoid space. ${ }^{6}$ This was followed immediately by the injection of a vasopressor, in the form of 8 to $16 \mathrm{mg}$. of methamphetamine hydrochloride, ${ }^{7}$ into the paravertebral muscles adjacent to the lumbar puncture site. The patient was immediately turned supine. The level of sensory anaesthesia at twenty minutes varied from $\mathrm{T} 4$ to $\mathrm{T} 10$. One patient

"This study was supported, in part, by grant 1-24 of the Ontario Heart Foundation and by Hoffman La Roche Ltd.

†Dr. Armstrong is a research fellow in anaesthesia (1965-66), St. Michael's Hospital and the University of Toronto. Dr. Finlayson is Assistant Professor, Department of Anaesthesia, St. Michael's Hospital and the University of Toronto. 
(\#14) did not receive methamphetamine, and a second (\#7) was given $10 \mathrm{mg}$. only after hypotension had developed 15 minutes following the anaesthetic injection. With this exception, vital signs in all patients were stable throughout.

\section{Sampling}

Blood samples were obtained from a central vein by the percutaneous insertion of a 24-inch polyethylene catheter, to eliminate tourniquet effect. ${ }^{8}$ Volume measurements were performed just prior to the onset of anaesthesia and again one hour later. For each measurement, multiple samples were taken through a three-way stopcock at $10,15,20$, and 30 minutes after injection of the isotopes. The total withdrawn was $55 \mathrm{ml}$. for each measurement. Catheter patency was maintained by slow infusion $(0.1 \mathrm{ml} . / \mathrm{min}$.) of 5 per cent dextrose in normal saline containing 1000 units of heparin per $500 \mathrm{ml}$. A maximum of $20 \mathrm{ml}$. of the solution was infused in the interval between the preanaesthetic and postanaesthetic measurements, including the quantities used to flush the catheter of isotope.

\section{Blood Volume Measurements}

Blood volumes were measured by radioactive isotope dilution after simultaneous injection of 40 to $50 \mu \mathrm{c}$. of autologous $\mathrm{Cr}^{51}$-tagged red cells and 0.8 to $2.0 \mu \mathrm{c}$. of $\mathrm{I}^{125}$-RIHSA (radio-iodinated human serum albumin) ${ }^{9}$ through the sampling catheter. The Volemetron apparatus was used.10-13

The red cell volume (RCV) was calculated by multiplying the whole blood volume, as measured from $\mathrm{Cr}^{51}$-tagged red cells in whole blood specimens, by the venous micro-haematocrit corrected by a factor of 0.98 for trapped plasma. ${ }^{14,15}$ Although these studies on plasma trapping were done using the Wintrobe method, it was assumed that the same degree of plasma trapping occurs with the microhaematocrit method, since it has been shown that haematocrit values obtained by the two methods are interchangeable. ${ }^{16}$ The plasma volume was measured directly after separation of plasma from the red cells.

Haematocrits were measured in triplicate, and an average of the three values was used as the final one for each specimen. The accuracy of these readings was \pm 0.5 per cent, and the haematocrits varied no more than 1.0 per cent at each time interval during a volume measurement.

Serum sodium, chloride, and potassium, were measured at the time of each volume study. In vitro measurements of known volumes of normal saline, using both isotopes, were performed weekly on the Volemetron with its power supply stabilized by voltage regulator. Accuracy of these determinations was within \pm 2 per cent.

The radioactivity of the venous catheters used was checked in a well-counter at the termination of each study, and showed no change from that of unused catheters. No significant change in electrolyte concentrations was seen.

\section{Results}

The absolute values for the red cell volume, plasma volume (PV), and whole blood volume (WBV) are shown in Table I. The per cent changes in these values 
TABLE I

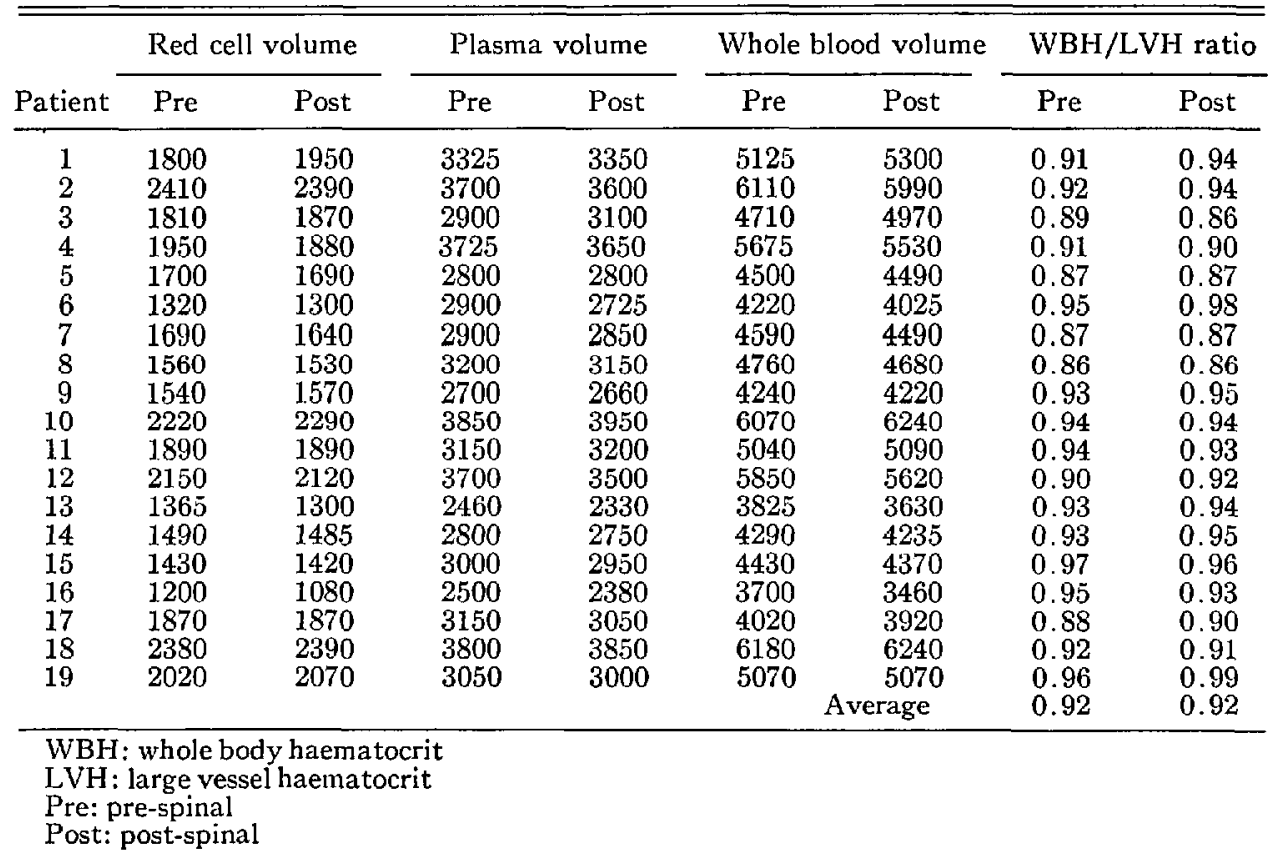

one hour after the onset of anaesthesia, as compared to the preanaesthetic values, are shown for RCV, PV, and WBV in Figures 1, 2, and 3 respectively.

Patient 14, who did not receive methamphetamine, showed no change in RCV $(0 \%)$, and a decrease in PV $(2 \%)$ and BV (1\%). Patient 7, who received methamphetamine only after the development of hypotension, showed decreases in RCV (3\%), PV (2\%), and BV (2\%). None of these latter changes were significant, nor were any of the remainder.

The whole body haematocrit was determined as the ratio of RCV to WBV. The whole body haematocrit/large vessel haematocrit ratio averaged 0.92 before and 0.92 after anaesthesia, and values for each volume measurement fell between 0.86 and 0.99 both before and after anaesthesia. This agrees with the range found by Chaplin ${ }^{17}$ and Fudenberg. ${ }^{18}$

\section{Discussion}

A summary of previous work in this field (Table II) shows that changes in blood volume and its components in man, attributable directly to spinal anaesthesia, have not been satisfactorily determined.

Dagher et $a l^{8}$ have claimed that the use of separate indicators and serial determinations for plasma and red cell volumes gives more accurate blood volume measurements than the use of a single indicator alone, since the WBH/LVH ratio may not be constant under all circumstances. All the studies in humans were done using a single indicator, and in association with a variety of 


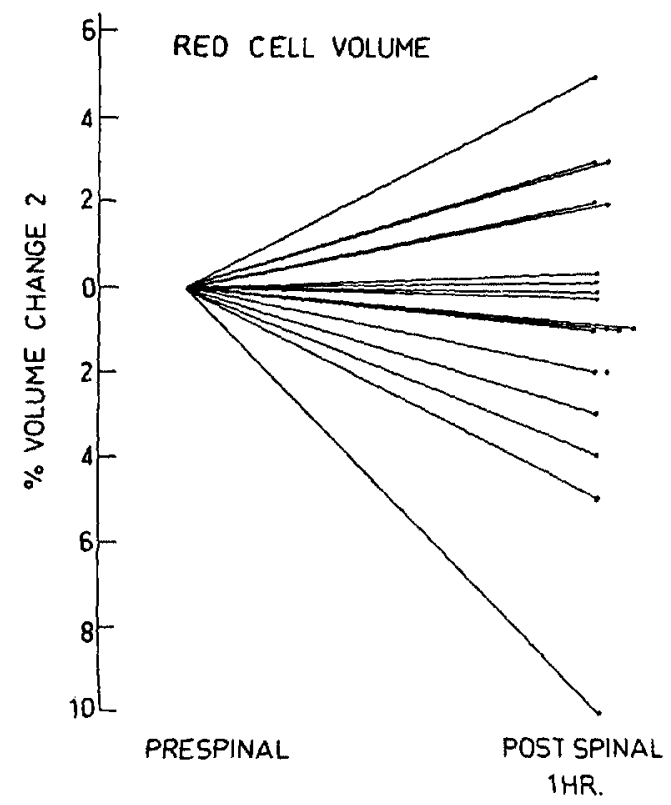

Ficure 1

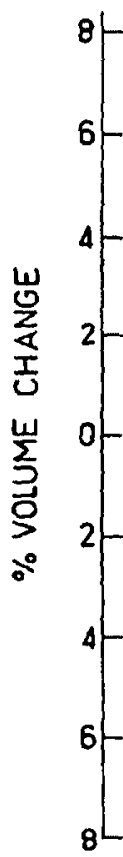

PLASMA VOLUME

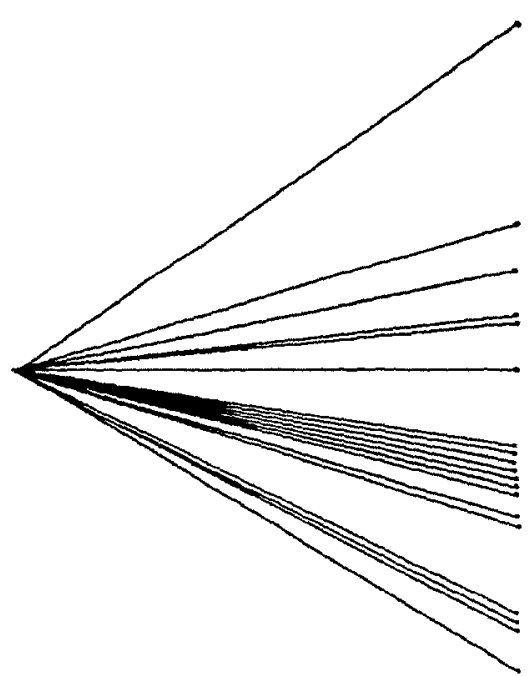

PRESPINAL

POSTSPINAL

1HR.

Figure 2 


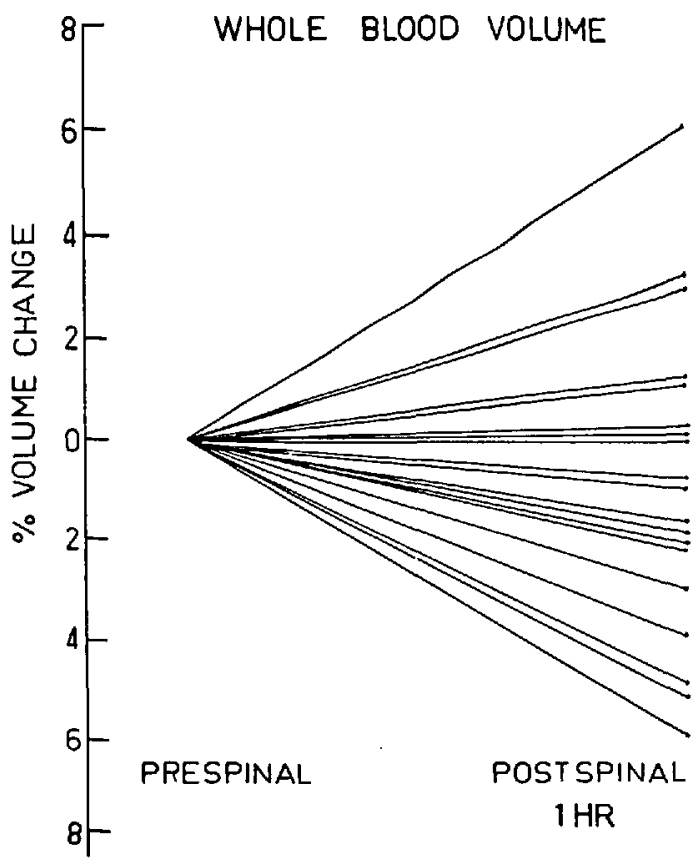

Figure 3

surgical procedures which could have altered blood volume ${ }^{1-4}$ One study, where separate indicators were used for red cell and plasma volumes, was done on cats and rabbits. ${ }^{5}$ Premedication was used in two studies. ${ }^{2,4}$ Wide variations in sampling times were employed, both before and after anaesthesia, and the results of the studies are conflicting.

The red cell compartment is a discrete component of the circulating blood volume which, in the absence of haemorrhage or transfusion, does not change. In certain shock-like conditions, a portion of the red cell volume may circulate more slowly in the vascular compartment, i.e. red cell sequestration may occur. ${ }^{19}$ It seems reasonable, then, that an anaesthetic which blocks a substantial section of the sympathetic system might alter the circulatory characteristics of the red cell mass and result in production of a slowly circulating fraction.

In such a circumstance, mixing of labelled red cells in the total red cell mass would be prolonged. Until mixing was complete, samples (with this method) would contain a higher concentration of labelled cells and yield a lower volume reading (e.g. at 10 or 15 minutes, as opposed to the 20 or 30 minute reading). However, neither the 10 nor the 15 minute volumes in the post-spinal period were significantly different from the 20 and 30 minute volumes, indicating that no sequestration of red cells occurred.

Albumin-bound plasma labels behave somewhat differently, in that they expand their distribution to include the total exchangeable extracellular protein pool. ${ }^{20}$ Under normal conditions, then, there is a continuous loss of plasma tag from the vascular compartment which might be affected by the altered haemodynamics of spinal anaesthesia. Multiple sampling after isotope injection with extrapolation 


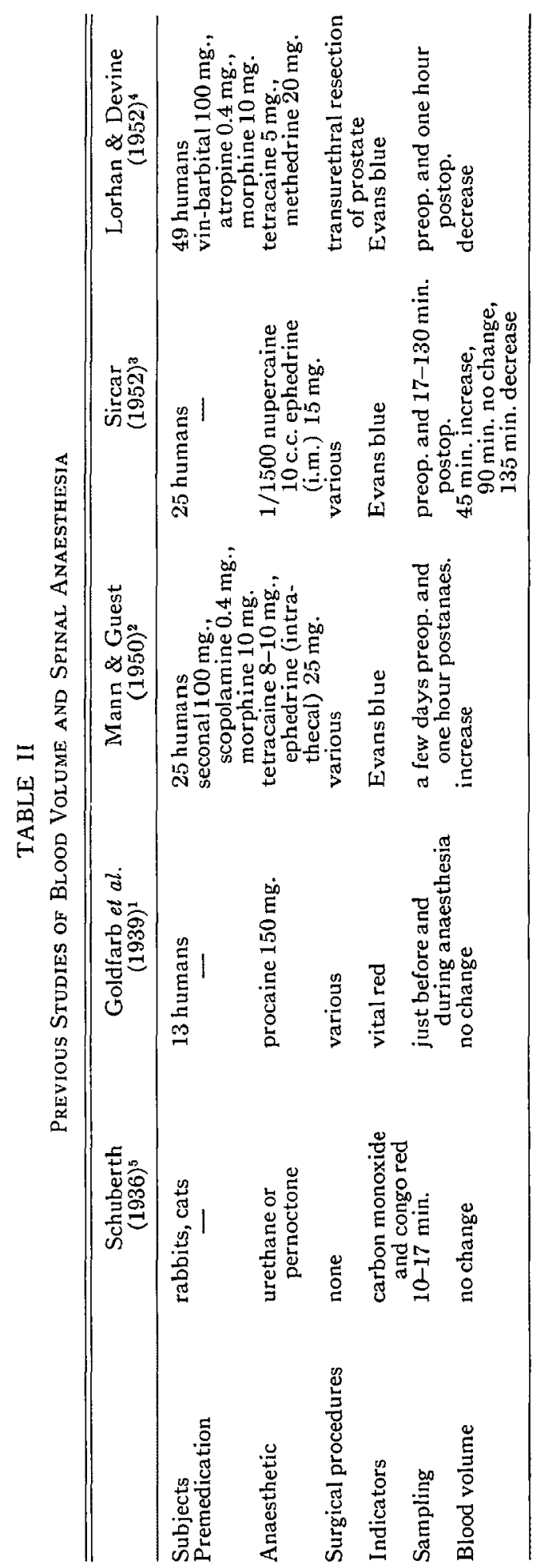


to time 0 would, theoretically, be required to compensate for this leakage. In this study, statistical analysis was made of plasma volumes obtained by: (a) computer extrapolation to time zero; $(b)$ the use of a single 20 minute value; and, (c) an average of the four values. It was found that there was no significant difference in the values obtained by the three methods, either before or after anaesthesia. The same was also found for the red cell volumes. Therefore, apart from attempting to detect the presence or absence of red cell sequestration, multiple sampling is not necessary in a study of this nature.

Changes in plasma volume with spinal anaesthesia would depend on the degree to which blood volume regulating factors were influenced, and the degree of compensation provided by the vasopressor. Since the volume regulating mechanisms ${ }^{21,22}$ are as yet imperfectly understood, no attempt can be made to speculate on how they would be affected by this method of anaesthesia.

The observation that no change in plasma volume occurred under spinal anaesthesia was supported by a lack of change in electrolyte concentrations.

These findings are similar to those reported in association with cyclopropane and contrast with the ten per cent increase in blood volume reported with halothane. ${ }^{23}$

\section{SUMmaRY AND CONCLUSIONS}

Blood volume studies were performed on 19 patients immediately before and one hour after the onset of spinal anaesthesia, using the radioactive techniques and the Volemetron apparatus. No change in red cell or plasma volumes and no red cell sequestration occurred with spinal anaesthesia.

The patients studied were in a state of negative fluid balance because they had been fasting overnight, and presumably had a contracted extracellular fluid volume. Methamphetamine counteracts hypotension by increasing cardiac output and peripheral resistance. It has some beta-receptor activity and produces vasodilatation in skeletal muscle and splanchnic vessels. It is conceivable, therefore, that the methamphetamine may have exaggerated the vasodilatation produced by the anaesthesia, and may have overcome the vasoconstriction that is known to occur in unanaesthetized areas. This dilatation, along with the possible diminished ability of the contracted extracellular fluid volume to shift into the vascular compartment, might explain the lack of any change in plasma volume.

\section{ACKNOWLEDGMENTS}

The authors wish to thank Miss S. Lapa, R.N., for technical assistance during this study; Dr. W. Reid of the Department of Epidemiology, University of Toronto, for the statistical analysis; and Dr. V. Colapinto and Dr. M. Barkin of the Urology Department, St. Michael's Hospital, for their help in completing this study.

\section{RÉSUMÉ}

On a utilisé une technique de dilution d'isotopes, à double indicateur, pour mesurer le volume des globules rouges et du plasma chez 19 malades qui subissaient une cystoscopie sous anesthésie rachidienne. On a mesuré ces volumes 
immédiatement avant l'anesthésie. Il ne s'est produit aucun changement sensible dans le volume des globules rouges ou du plasma.

\section{REFERENCES}

1. Goldfarb, W.; Provisor, B.; \& Koster, H. Circulation during Spinal Anesthesia. Arch. Surg. 39: 429 (1939).

2. MANN, L. S. \& GUEST, S. I. Early Effects of Spinal Anesthesia and Surgery on Blood Volume in Man. Am. J. Physiol. 161: 239 (1950).

3. Sircar, P. A Study of the Circulating Blood Volume under Anesthesia: 3. Spinal Anesthesia. J. Indian M.A. 21 : 340 (1952).

4. Lorhan, P. H. \& Devine, M. M. Blood Volume during Low Spinal Anesthesia. Am. Surg. 18: 179 (1952).

5. Schubertr, O. O. On the Disturbance of the Circulation in Spinal Anesthesia. Acta chir. scandinav. 78: 43, suppl. (1936).

6. Dhipps, R. D.; Eckenhoff, J. E.; \& Vandam, L. D. Introduction to Anesthesia: The Principles of Safe Practice. 2nd ed., Philadelphia: W. B. Saunders Co., chap. 17, 1961.

7. Goodman, L. S. \& Gilman, A. The Pharmacological Basis of Therapeutics. 3rd ed., Toronto: Collier-Macmillan, 1965, p. 503.

8. Dagher, F. J.; Lyons, J. H.; FinLayson, D. C.; Shamsat, J.; \& Moone, F. D. Blood Volume Measurement: A Critical Study, in Advances in Surgery, vol. 1, Chicago: Year Book Medical Publishers, 1965, p. 69.

9. Operating Manual, Volemetron, Ames Atomium. Billerica, April, 1965.

10. MYrHe, E. \& RuSTAD, H. Blood Volume Determinations with Cr ${ }^{51}$-labelled Red Blood Cells. Act. chir. scandinav. 125: 197 (1963).

11. Buckwalter, J. A.; Ferguson, J. R.; Johnson, R. J.; \& Soper, R. J. Blood Volume Measurement with a New Instrument. Arch. Surg. 86: 874 (1963).

12. Gruber, U. R. \& Allgower, M. The Use of the Volemetron for Blood Volume Measurements: A Critical Analysis. Bull. Soc. Int. Chir. 2: 218 (1964).

13. Greter, J. M.; Lirwin, S. B.; \& Naroi, G. L. Comparative Study of a New Device for Measuring Blood Volume. Arch. Surg. 86: 164 (1963).

14. Chaplin, H. \& Mollison, P. L. Correction for Plasma Trapped in the Red Cell Column of the Hematocrit. Blood. 7: 1227 (1952).

15. Eвough, F. G.; Levine, P.; \& Emerson, C. P. Trapped Plasma in Red Cell Mass of the Hematocrit Tube. J. Lab. Clin. Med. 46: 409 (1955).

16. McGovern, J. J.; Jones, A. R.; \& Steingerg, A. G. The Hematocrit of Capillary Blood. New England J. Med. 253: 308 (1955).

17. Chaplin, H.; Mollison, P. L; \& Vetrer, H. The Body Hematocrit Venous Hematocrit Ratio: Its Constancy over a Wide Hematocrit Range. J. Clin. Invest. 32: 1309 (1953).

18. Fudenberg, H.; Baldint, M.; Mahoney, J. P.; \& Dameshek, W. Body Hematocrit, Venous Hematocrit and the Splenic Reserve. Blood. 17: 71 (1961).

19. Suzuki, F.; Baker, R. J.; \& Shoemaken, F. C. Red Cell and Plasma Volume Alterations after Hemorrhage and Trauma. Ann. Surg. 160: 263 (1964).

20. Lawson, H. C. Handbook of Physiology (section 2: Circulation), vol. 1. Baltimore: Williams and Wilkins (1962), p. 23.

21. Pearce, J. A Current Concept of the Regulation of Blood Volume. Brit. Heart J. 23: 6 (1961).

22. Mayerson, H. S. Blood Volume and Its Regulation. Ann. Rev. Physiol, 27: 307 (1965).

23. Grable, E.; Finch, A. J.; Abrams, A. L.; \& Williams, J. A. The Effect of Cyclopropane and Halothane on the Blood Volume in Man. Anesthesiology. 23: 828 (1962). 